\title{
The Moderating Effect of Mandatoriness on the Acceptance of Mobile Phone Technology: SMEs Perspective
}

\author{
Renatus Mushi \\ The Institute of Finance Management (IFM), P. O. BOX 3918, Dar es Salaam, Tanzania.
}

Received: 21 April 2018; Accepted: 25 May 2018; Published: 08 September 2018

\begin{abstract}
The mobility and pervasiveness have created many opportunities of using mobile phones in performing activities of SMEs. This is due to the low ICT readiness especially in SMEs operating in less developed countries compared to large firms. Some of the challenges facing Tanzanian SMEs include but are not limited to poor ICT infrastructures, lack of ICT skills, lack of management support, poor financial capabilities and lack of reliable electrical power supply.

While there is a number of studies which explains the factors influencing adoption and usage of mobile phones in SMEs, it is still unclear whether the mandatoriness has an impact on such acceptance. Understanding the voluntary aspects provides informed decision-making for SME managers and potential stakeholders on identifying the issues which needs their attention. This study involved a survey of 459 respondents from Tanzanian SMEs using SEM and AMOS. The results show that the mandated use of mobile phones in the SMEs has a moderating effect on the overall acceptance of mobile phones in performing daily activities. Recommendations and suggestions for future works are also highlighted in this article.
\end{abstract}

(C) 2018 Published by MECS Publisher. Selection and/or peer review under responsibility of the Research Association of Modern Education and Computer Science

\section{Introduction}

The literature is a rich with models and theories that explain the acceptance of technological innovations in different contexts (Byomire \& Maiga, 2015; Davis, 1989; Prieto, Migueláñez, \& García-Peñalvo, 2015; Venkatesh, Morris, Davis, \& Davis, 2003). Some of them are more specific in terms of technology (like.eLearning, mobile phones, cloud computing and desktop computing) and others are in terms of operational contexts (like in the hotels, healthcare environment and primary schools). The majority of technology acceptance models explains the adoption of desktop computing technology in different geographical,

\footnotetext{
* Corresponding author.

E-mail address: renatus.michael@gmail.com
} 
sectorial and firm-size contexts (Davis, 1989b; Venkatesh et al., 2003; Venkatesh and Bala, 2008). Few studies have adopted, modified and tested such models in the organisational contexts, SMEs in particular. This study model the factors which influence SMEs employees' acceptance of mobile phone technology in SMEs by extending the Technology Acceptance Model (TAM). Special focus will be on studying whether or not the working environment in the SMEs in terms of the relationship between managers and ordinary employees have an impact on the acceptance of mobile phone technology. The deliverable of this research is a model which shows key factors which influence acceptance of mobile phones and discussions concerning the impact of mandatoriness on its usage. This will provide opportunities for SME's managers and other key stakeholders to identify the best ways of managing acceptance of mobile phones through intentions of users. The next sections of this paper are organised as follows: Section two provides the background of this study followed by an introduction to TAM in Section three. The SMEs are defined in section four followed by the discussions concerning mandatoriness and its influence on the acceptance of technology section five. Related works are presented in section six followed by a research design in section seven. The methodological details of this study are discussed in section eight followed by the results in section nine. Section ten concludes this paper and presents the future work.

\section{Research Background}

This study performs analysis of existing theories, models and methods which explais the acceptance of technologies. The assumptions are based on the theoretical foundations which suggest that the human behaviour and perceptions on different aspects of life have a significant effect on his/her present and future actions (Davis, 1989; Fishbein \& Ajzen, 1975). Taking from this perspective, the intentions and usage of mobile phones by the employees of SMEs are assumed to be influenced by their personal perceptions towards a number of factors, including the way they respond to the queries while performing their duties by using mobile phones as the dependable technology. Some of the factors have already been explained and tested in previous studies in other contexts (Byomire \& Maiga, 2015; Prieto et al., 2015; Sun, Wang, Guo, \& Peng, 2013; van Biljon \& Kotzé, 2007). Other insights were borrowed from studies which have successfully extended TAM in explaining other factors such as job relevance (Kim, 2008).

The deliverable of this study is a tested model that show the factors influencing intentions and use of mobile phones by employees and managers of SMEs. Afterwards, theoretical and practical implications will be discussed. The main research question is 'does mandatoriness on using mobile phones at workplaces matter in SMEs?' The theoretical model will be designed and tested to assess if the proposed hypotheses will be supported or not.

\section{Technology Acceptance Model (TAM)}

This study extends the Technology Acceptance Model (TAM) (Davis, 1989). TAM identified the factors that facilitate the integration of technologies into an organisation, to discover why users accept or reject a technology (Davis, 1989). The development of TAM was based on adopting the concepts of the Theory of Reasoned Action (TRA) (Fishbein \& Ajzen, 1975), a more generalised theory, which explain specific contexts (Lindsay, Jackson, \& Cooke, 2011). In social psychology, TRA has been used to explain why people perform a particular behaviour in situations of 'reasoned action' through identifications of causal relationships that exist between beliefs, attitudes, intentions and behaviour (Kwon \& Chidambaram, 2000; Pedersen, 2005). TAM theorises that when users are given a piece of technology, there are several factors which influence their decisions on how and when they will use such technology (Davis, 1989; Yueh, Lu, \& Lin, 2015).

TAM explains the acceptance of technology by two key perceived attributes or measures: perceived usefulness (PU) and perceived ease of use (PEU). According to Davis (1989), PU is whether the technology will enhance the user's job performance whereas PEU relates to what extent using the system will be free from effort. 
The integrity of original TAM has been tested through a number of empirical studies, which extends the model to different settings, providing consistency and good reliability and confirming its validity (Lindsay et al., 2011; Venkatesh \& Davis, 2000). In this regard, TAM is arguably the best model to provide a foundation for explaining the issues which motivate the adoption of mobile phone technology in Tanzanian SMEs.

\section{SMEs}

Small and Medium Enterprises (SMEs) are defined in terms of capital investments and the number of employees. For instance, the Organization for Economic Co-operation and Development (OECD) definition is based on employment figures and defines SME as the companies having less than 500 employees (OECD, 2004). In Britain, SMEs are enterprises which have an annual turnover of $£ 2$ million or less with fewer than 200 paid employees whereas, in Australia, SMEs are defined as enterprises with between five and 199 employees (Migiro, 2006). In the European Union (EU), small businesses have fewer than 50 employees with an annual turnover not exceeding $€ 10$ million and a balance sheet total that is beyond $€ 10$ million (Avram \& Kühne, 2008). The World Bank defines a micro-scale company as the one having less than 50 employees, a small-scale company as having 50 employees and a medium-scale company as having 50-200 employees (Kiriş \& Kiriş, 2008).

In Tanzania, Mawona and Mpogole (2013) state that SMEs are companies that are limited to the number of employee (also called headcounts) and profit or capital. The Tanzania Small Industries Development Organisation (SIDO) document highlights that in the event of an enterprise falling under more than one category, the level of investment will be the deciding factor (SIDO, 2002). On the other hand, the Tanzanian Revenue Authority (TRA) defines a small business as the one whose annual taxable turnover is less than TZS 40 Million (USD 22,500). The definition of an SME in this study is, therefore, any company which have a maximum working capital of $\$ 444,400$ and headcounts of less than 99 .

\section{Mandatoriness on Technology Use}

This study focuses on the impact of mandatoriness on using a mobile phone technology in SMEs. On testing this factor, this study will refer to mandatoriness in the form of voluntariness. It has been common to find that employee's uses a technology for work wither because they want to impress their bosses, scared to annoy their bosses or because such technology is the only enabler in performing their duties effectively. Under such circumstances, such employees are subjected to a mandated use of technology (Kelman, 1958).

In the context of this study, voluntariness refers to the extent to which users feel that they can use a mobile phone technology whenever they want (voluntarily) and not under a particular force from anybody else. In principle, subjective norm includes opinions from the peers such as friends, family and clients concerning the individuals on using or not using a technology (Davis, 1989; Venkatesh \& Davis, 2000). Despite the fact that subjective norm can be affected by the said groups of people, this study pays a special attention to the employeeboss relationship at work. The main assumption here is that the relationships which are associated with subjective norm will tend to be involved only when the working environment change from the mandated use of technology to the non-mandated use of technology. Therefore, the aim is to test and assess whether the voluntariness is statistically moderating the relationship between subjective norm and behaviour intention.

\section{Related Work}

The impact of mandatoriness on the usage of technologies at company level have been discussed in several perspectives. Venkatesh and Bala (2008) performed a longitudinal study by investigating the factors which influence acceptance of desktop computing technology by extending the TAM model. They found that voluntariness is among the factors which influence the perceived usefulness of a technology.

That means, the more a technology is perceived to be used under the influence of bosses or job requirements will more likely influence its perception of usefulness. 
The fact that mobile phones are used to perform the majority of activities of SMEs, means there is a great possibility that the employees are not actually using a technology voluntarily. This rises a concern that the use of thechnology is under a 'forced' situation. There is a scarce of literature which has studied such working context and comment whether or not there is an impact on the usability of mobile phones because of mandatoriness.

\section{Theoretical Model Design}

The theoretical model will be developed by the hypotheses which are formulated in this section. The perceived usefulness of the technology and perceived ease of use have found to influence the directly influence the behavioural intentions in using technologies (Kim et al., 2008; Tassabehji et al., 2008; van Biljon and Kotzé, 2007). PEU influences PU due to the fact that, PEU indirectly tends to influence the intention to adopt technology and finally its usage (Gallego et al., 2008; Peng et al., 2012; van Biljon and Kotzé, 2007). Therefore it is posited that the following hypotheses should be true:

H1a: Perceived ease of use (PEU) of mobile phone technology will positively influence the employees' perceived usefulness $(P U)$ :

HIb: Perceived ease of use (PEU) of mobile phones will positively influence the employee's behaviour intention (BI):

H1c: Perceived usefulness (PU) of mobile phones will positively influence the employee's behaviour intention (BI):

H1d: Employees behavioural Intention (BI) of using mobile phones on will influence its actual usage (U):

Subjective norm is another important factor which is key to the working environments of SMEs. Subjective norm refers to the influence of the peers on the individual's decision to perform the behaviour in question (Venkatesh, 2000). In the context of using mobile phone technology, friends, family members, clients and bosses can play part in the form of subjective norm. Therefore, this study hypothesises that:

H2a: Subjective Norm (SN) will positively influence Perceived Usefulness (PU) of mobile phone technology:

H2b: Subjective Norm (SN) will positively influence behavioural Intention (BI) to use mobile phone technology:

Mobile phones are used by employees to perform both work and personal obligations. Unlike in traditional computing where both users and computing devices are stationary and the use of the device takes place at the same place and familiar location, mobile devices change the physical, social and cultural contexts in which users interact with the system (Ruuska-Kalliokulj et al., 2001). Since managers have a tendency of calling ordinary employees asking for explanations of various matters or providing instuctions, there is a sort of mandatory nature in the usage of mobile phones.. In such scenario, if some of the tasks have to performed by using mobile phones, it means employees do not have any other alternative other than using it. That means the use of mobile phones in the SMEs is no more voluntary in nature. Based on such situation, the following hypotheses are assumed to be true:

H3a: Voluntariness (VOL) will moderate the effect of Subjective Norm on the Perceived Usefulness (PU) of mobile phone technology:

H3b: Voluntariness (VOL) will moderate the effect of Subjective Norm (SN) on the Behavioural Intention (BI) of using mobile phone technology: 


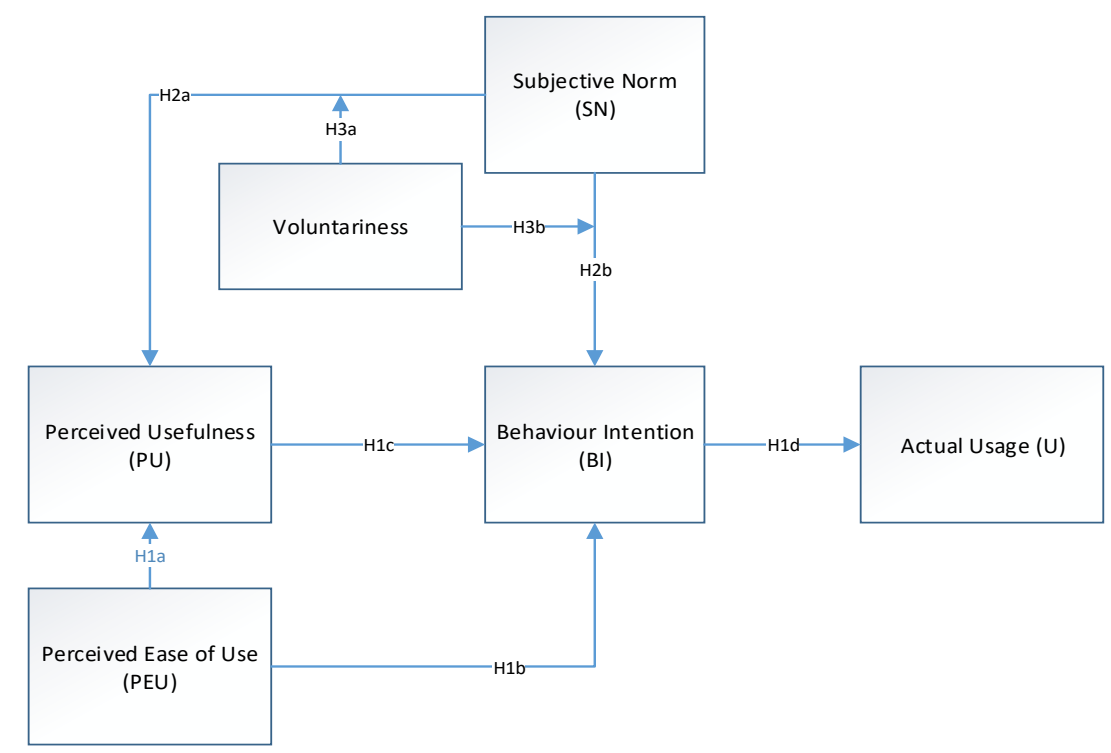

Fig.1. A Theoretical Model

\section{Research Methodology}

The questionnaires were prepared in which each construct was represented by the measurement items. The validity of the questionnaire was assessed by performing face validity to the experts as well as the Item Content Validity Index (I-CVI) (Polit \& Beck, 2006) in which all items attained acceptable values of I-CVI. The assessment of outliers and normality were also performed in which all the measurement items were assessed. Normality was assessed by using the kurtosis values in which there is no significant normality problem. Also, the normality details show that the multivariate critical ration (c.r) was greater than 5 which is the recommended threshold value (Baraldi \& Enders, 2010). Therefore, the normality aspect will not cause any significant impact on the results. The tolerance for correlations was found to be above 0.25 which is the minimum recommended value (Huber \& Stephens, 1993).

Also, the multicollinearity details showed that the Variance Inflation Factor (VIF) values were all less than 10 which is also acceptable in accordance with Hair et al (2008). This means that the factors which have been extracted from the data do not have multicollinearity problem. Table 1 shows the information of model fit indices with the corresponding minimum requirements. Therefore, the data set were confirmed to match with the predicted conceptual model seen in Fig 1.

Table 1. Model Fit Indices of the Model

\begin{tabular}{|l|l|l|l|}
\hline Model fit parameter & RMSEA & CFI & ChiSq/df \\
\hline Required value & $<0.08$ & $>0.90$ & $<3.00$ \\
\hline Attained Value & 0.054 & 0.937 & 1.671 \\
\hline
\end{tabular}




\section{Results and Discussions}

The results of this study are discussed in two parts. The first set of results shows the significant results of each of the direct relationships of the designed model as a part of testing the hypotheses. This part will discuss which relationships are non-significant indicating that they do not deserve to remain in the final model. The second category of results describes the moderation effect which is caused by voluntariness on the relationship of the subjective norm to those of perceived usefulness and behaviour intention factors.

\subsection{Direct Relationships Results}

The structural model was run and the estimates in the regression analysis yield the information shown in Table 2. This table displays the information necessary to interpret the hypotheses of the model which was tested against the data. Since the moderating constructs are not tested at this stage, these results measure only direct relationships depicted in the model.

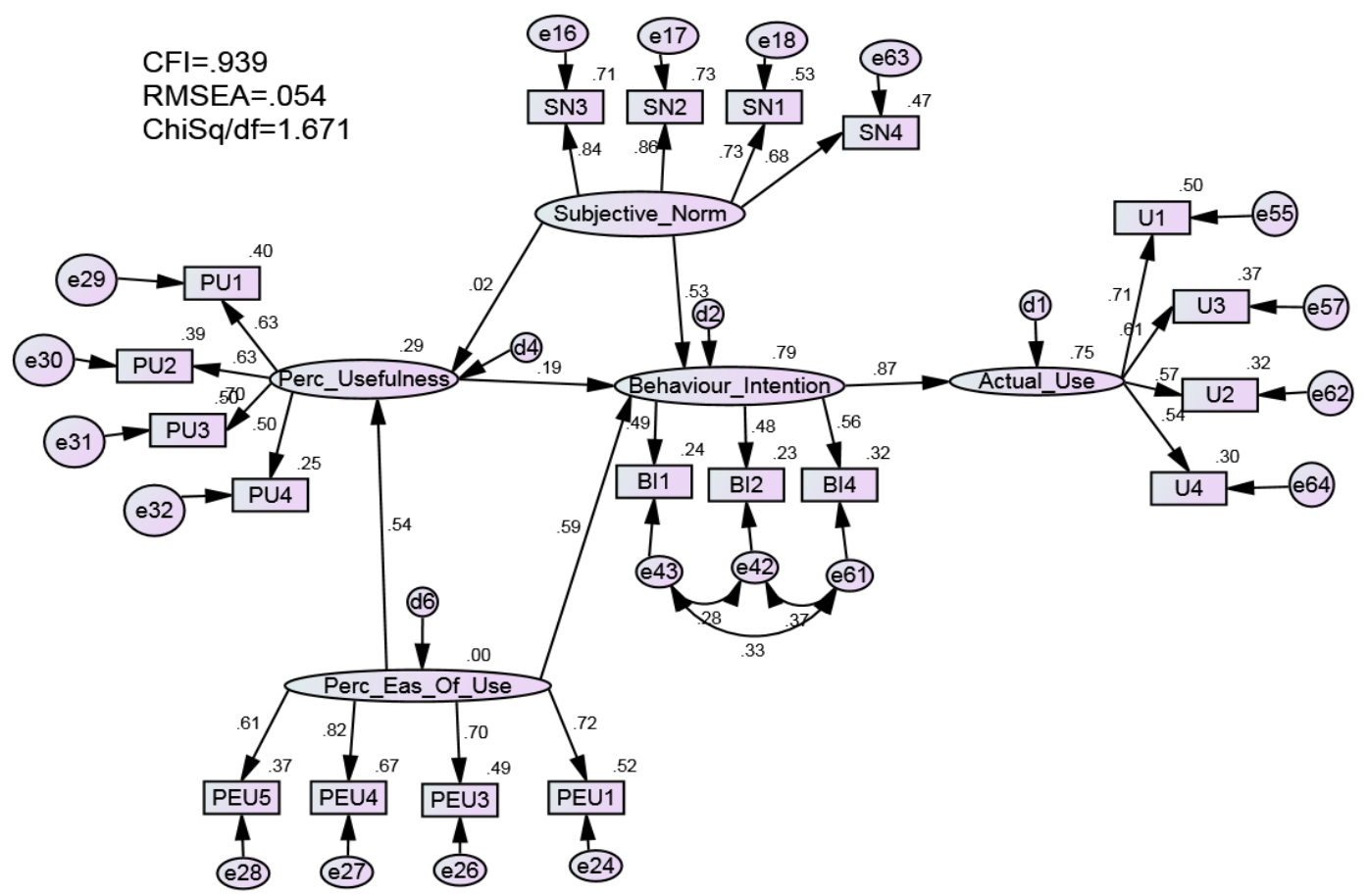

Fig.2. A Structural Model of the Study

The results of this study support hypothesis $H 2 a$. The results show that subjective norm has a positive impact on the positive influence on the perceived usefulness in the SMEs context. This is not a surprise especially on the use of mobile phones in the working scenarios like the SMEs context because it is impossible not to use mobile phones at work at all. The clients, family members and friends are likely to think that the use of mobile phones is like a built-up culture to all employees of the SMEs. 
Table 2. Path Analysis results for a model

\begin{tabular}{|l|l|l|l|l|l|l|l|}
\hline \multicolumn{2}{|l|}{ Standardised Regression Weights } & Estimate & S.E & C.R & P & Label \\
\hline Perc_Usefulness & $\leftarrow$ & Subjective_Norm & 0.269 & 0.052 & 5.158 & $* * *$ & H2a \\
\hline Perc_Usefulness & $\leftarrow$ & Perc_Eas_Of_Use & 0.638 & 0.087 & 7.29 & $* * *$ & H1a \\
\hline Behaviour_Intention & $\leftarrow$ & Subjective_Norm & 0.295 & 0.043 & 6.875 & $* * *$ & H2b \\
\hline Behaviour_Intention & $\leftarrow$ & Perc_Usefulness & 0.066 & 0.046 & 1.454 & 0.146 & H1c \\
\hline Behaviour_Intention & $\leftarrow$ & Perc_Eas_Of_Use & 0.309 & 0.065 & 4.779 & $* * *$ & H1b \\
\hline Actual_Use & $\leftarrow$ & Behaviour_Intention & 1.358 & 0.174 & 7.785 & $* * *$ & H1d \\
\hline
\end{tabular}

Where: C.R-Critical Ratio, S.E-Standard Error, $* * * \mathrm{P}<0.05$

This study had also hypothesised that perceived ease of use has a direct influence on perceived usefulness. This was also supported by a number of studies in the context of acceptance of mobile phone technology (Gallego, et al. , 2008; Kwon \& Chidambaram, 2000). The results of this study support this hypothesis (Hla). That means the more the employee perceives that mobile phones are easy to use, the more they perceive that it is useful to them. One of the studies which have not identified the relationship between perceived ease of use and perceived usefulness is the study which investigated the initial acceptance of integrating mobile commerce in into an organisational process (Gribbins, Shaw, \& Gebauer, 2003). In such study, the users were unaware of how mobile wireless mobile commerce will improve business processes when integrated to the existing applications. The study was still a pilot study in which the mobile commerce systems were not yet there so users had a poor experience in using a technology. Therefore, there is a high probability that they were not sure of how the system can be easy to use. The challenge of assessing the factor concerning a system, which is not applicable at the time of the study, is mainly on understanding the measurement items in the user perspectives.

On the other hand, the result of this study supports this hypothesis $H 2 b$ which implies that the subjective norm has a significant relationship with an intention of employees to use mobile phones in their SMEs. Working under SMEs using a mobile phone is assumed a non-voluntary action. Therefore, people who are close to the employees such as friends, peers, clients and family members are likely to think that the use of mobile phone is essential. In that regard, an employee is likely to intend to use it in future.

The direct influence of Perceived Usefulness to Behaviour Intention (HIc) was also hypothesised in this study. The results show that the relationship between perceived usefulness and behaviour intention in the Tanzanian SMEs was not supported. This suggests that the perception of the usefulness of mobile phone technology in their activities does not influence their intention to use it in future. This observation is in line with a study on the employee acceptance of integrating mobile commerce in their workplaces in which perceived usefulness did not have a significant influence on their behaviour intention (Gribbins et al., 2003).

The direct influence of Perceived Ease of Use on behaviour Intention $(H 1 b)$ was also found to be supported. The results of this study are in line with the context of acceptance of smartphones (Chen et al. 2009) and employees acceptance of mobile commerce (Gribbins et al., 2003). This implies that if employees of SMEs perceive that it is easy to use mobile phones then it will be useful in their work.

Lastly, the results show the behaviour intention influences directly the actual usage, supporting HId. There is a statistically significant relationship between behavioural intention and actual usage of mobile phone technology in SMEs. This implies that, as employees feel intending to use a mobile phone in performing their SME obligations, they will actually use it. The results concerning moderating relationships are shown in the following sections 


\subsection{Moderating Effect of Voluntariness}

The proposed conceptual framework included moderating factors which influence other direct relationships. These factors are voluntariness which moderates the relationship between social influence-behaviour intention and social influence-perceived usefulness relationship and job relevance which moderate the relationship between perceived usefulness and behaviour intention. The approach which was used was adopted from Awang (2015) and (Zhao \& Cavusgil, 2006).

In such approach, the data of the moderating variables are sorted in ascending order followed by distributing the data set into two equal data sets; one data set for low values of moderating variables and another for high values of moderating variable. A structural model is then executed with each of the data sets one at a time. With the high value of moderating variable, model fit indices are collected when a relationship under investigation is constrained and when it is not constrained to 1 while recording the Chi-Square (cmin) and Degree of Freedom (df) in each of the results (Awang, 2015). The differences of the values of CMIN and DF between the constrained and not constrained pairs are recorded for both low values and high values where the conclusion is drawn.

Before proceeding to the next steps of this section it is essential to understand the meaning of voluntariness in the context of this study. Since the datasets were segmented into high standardised values and low standardised values of moderating variables, the same segmentation is done for voluntariness as it moderates the relationships between subjective norm and behaviour intention and that of subjective norm and perceived usefulness. However, the key information is that when the voluntariness is high this it means there is a high level of compliance on using mobile phone technology within SMEs and the opposite applies for low voluntariness.

\section{A. Moderation Effect of Voluntariness on Subjective Norm to Perceived Usefulness relationship}

This study hypothesised that the relationship between subjective norm and perceived usefulness would be affected or moderated by voluntariness. The response values of voluntariness were standardized and sorted in descending order to get two datasets. This allows extracting datasets which correspond to high standardised values of voluntariness and those of low standardised values. In simple words, the model which results from the dataset of high standardised values of voluntariness corresponds to a predicted conceptual model which assumes a maximum level of voluntariness and the opposite applies to the data sets of low standardised values of voluntariness. The CMIN and DF parameters obtained under default condition and after constraining the SN-PU relationship to 1 are as seen in Table 3 and Table 4 respectively. The difference between the cmin and df is noted in order to compare with the same information from the low values of voluntariness.

Table 3. CMIN values for Low Voluntariness

\begin{tabular}{|l|l|l|l|l|l|}
\hline LOW Vountarines (SN-PU Unconstrained to 1) \\
\hline Model & NPAR & CMIN & DF & P & CMIN/DF \\
\hline Default model & 47 & 238.907 & 143 & 0 & 1.671 \\
\hline Saturated model & 190 & 0 & 0 & & \\
\hline Independence model & 19 & 1754.544 & 171 & 0 & 10.26 \\
\hline LOW Voluntariness (SN-PU Constrained to 1) & NPAR & CMIN & DF & P & CMIN/DF \\
\hline Model & 46 & 316.165 & 144 & 0 & 2.196 \\
\hline Default model & 190 & 0 & 0 & & \\
\hline Saturated model & 19 & 1754.544 & 171 & 0 & 10.26 \\
\hline Independence model & \multicolumn{7}{|l|}{ CMIN difference=77.258 } & & \\
\hline DF difference=1 &
\end{tabular}


Table 4. CMIN values for High Voluntariness

\begin{tabular}{|l|l|l|l|l|l|}
\hline HIGH Vountarines (SN-PU Unconstrained to 1) & NPAR & CMIN & DF & P & CMIN/DF \\
\hline Model & 47 & 221.722 & 143 & 0 & 1.551 \\
\hline Default model & 190 & 0 & 0 & & \\
\hline Saturated model & 19 & 1056.595 & 171 & 0 & 6.179 \\
\hline Independence model & \multicolumn{5}{|l|}{} \\
\hline HIGH Vountarines (SN-PU constrained to 1) & NPAR & CMIN & DF & P & CMIN/DF \\
\hline Model & 46 & 251.045 & 144 & 0 & 1.743 \\
\hline Default model & 190 & 0 & 0 & & \\
\hline Saturated model & 19 & 1056.595 & 171 & 0 & 6.179 \\
\hline Independence model & CMIN difference=29.323 & \\
\hline DF difference=1 &
\end{tabular}

According to Awang (2015), if the difference of both of the values of CMIN differences is greater than 3.84, the moderated effect of the variable which was constrained treated high and low to the relationship is considered to be statistically significant. The CMIN difference values for when voluntariness was split into low dataset 77.258 and 29.323 for high values of voluntariness which results in a difference of $(77.258-29.323=47.935)$ Since 45.022 is greater than 3.84 , the moderated effect of voluntariness on the relationship between subjective norm and behaviour Intention is statistically significant, thereby supporting the H3a hypothesis.

Even though there is a significant effect posed by voluntariness on SN-PU relationship, it is still unclear under which circumstances the relationship is more pronounced. Awang (2015) and Zhao and Cavusgil (2006) proposed a mechanism of identifying in which case the moderating variable is more pronouncing than the other. By adopting their approach, the standardised regression weights of the SN-PU relationship were extracted using datasets of high values of voluntariness and the same applies to the low values of voluntariness while checking the estimate values and the significance of the relationships. The results are seen in Table 5.

Table 5. Description of the type of Voluntariness Moderation on SN-PU

\begin{tabular}{|c|c|c|c|c|c|c|}
\hline \multicolumn{3}{|c|}{ Regression Weight SN-BI (High Voluntariness) } & Estimate & S.E. & C.R. & $P$ \\
\hline Perc_Usefulness & $\leftarrow$ & Subjective_Norm & 0.277 & 0.089 & 3.127 & 0.002 \\
\hline \multicolumn{3}{|c|}{ Regression Weight: SN-BI(Low Voluntariness) } & Estimate & S.E. & C.R. & $\mathrm{P}$ \\
\hline Perc_Usefulness & $\leftarrow$ & Subjective_Norm & 0.021 & 0.074 & 0.286 & 0.775 \\
\hline
\end{tabular}

According to Zhao and Cavusgil (2006) and Awang (2015), a set with high estimates indicates that it is more pronounced than the other. Also, it will be regarded as a partial moderation if in both cases the relationships are statistically significant $(\mathrm{p}<0.05)$ and full moderation if one of them is found not statistically significant. In that case, Table 5 depicts two main observations.

Firstly, since the estimate at high voluntariness $(0.277)$ is greater than the estimate at low voluntariness $(0.021)$ implies that the effect of subjective norm (SN) on perceived usefulness (PU) is more pronounced in high voluntariness to low voluntariness. That means the more employee feels that they impress their bosses by using mobile phones or scared to annoy them by not using mobile phones effectively when performing SMEs activities, the more impact the subjective norm will have on the perceived usefulness. 
Secondly, since the relationship between $\mathrm{SN}$ and PU on high voluntariness is statistically significant (with $\mathrm{P}=0.002$ (which is $<0.05$ )) while the same relationship is not statistically significant (with $\mathrm{P}=0.775$ (which is not $<0.05)$ ) then the moderation which exists is full moderation. That means, when voluntariness is very high, subjective norm tends to influence the perceived usefulness whereas when the voluntariness is not there the influence of subjective norm to perceived usefulness disappears. In that case, the usage context of mobile phone technology in the SMEs under the situations of low voluntariness is as the same as a typical environment where users of a technology are free to choose to use or not to use a technology.

\subsection{Moderation Effect of Voluntariness on Subjective Norm to Perceived Usefulness relationship}

This study also hypothesised that voluntariness would moderate the relationship between subjective norm and behaviour intention. This was based on the assumption that whenever employee think that the use of mobile phones will impress their bosses or if they do not use them at their workplaces would annoy their bosses will moderate the influencing relationship between subjective norm and behaviour intention.

The same procedure which involves splitting the moderator variable into a standardised high dataset and standardised low values data sets were used followed by collecting the values by default and when constraining the relationships to 1 .

The values of voluntariness were standardised and sorted in descending order to get two datasets; high voluntariness dataset and low voluntariness data sets. The parameters obtained under the default condition and after constraining the SN-BI relationship is as seen in Table 6 and Table 7 respectively.

Table 6. Model Fit Indices for Low Voluntariness (SR-BI)

\begin{tabular}{|l|l|l|l|l|l|}
\hline LOW Voluntariness (SN-BI Unconstrained to 1) & NPAR & CMIN & DF & P & CMIN/DF \\
\hline Model & 47 & 238.907 & 143 & 0 & 1.671 \\
\hline Default model & 190 & 0 & 0 & & \\
\hline Saturated model & & & & & \\
\hline Independence model & 19 & 1754.544 & 171 & 0 & 10.26 \\
\hline LOW Voluntariness (SN-BI Constrained to 1) & CMIN & DF & P & CMIN/DF \\
\hline Model & NPAR & 289.621 & 144 & 0 & 2.011 \\
\hline Default model & 46 & 0 & 0 & & \\
\hline Saturated model & 190 & 1754.544 & 171 & 0 & 10.26 \\
\hline Independence model & 19 & CMIN difference=50.714 & & \\
\hline DF difference=1 & & \multicolumn{2}{|l|}{0} & & \\
\hline
\end{tabular}


Table 7. Model Fit Indices for High Voluntariness (SN-BI)

\begin{tabular}{|l|l|l|l|l|l|l|}
\hline HIGH Vountarines (SN-BI Unconstrained to 1) & CMIN & DF & P & CMIN/DF \\
\hline Model & NPAR & 221.722 & 143 & 0 & 1.551 \\
\hline Default model & 47 & 0 & 0 & & \\
\hline Saturated model & 190 & & & & \\
\hline Independence model & 19 & 1056.595 & 171 & 0 & 6.179 \\
\hline HIGH Vountarines (SN-BI constrained to 1) & CMIN & DF & P & CMIN/DF \\
\hline Model & NPAR & 235.213 & 144 & 0 & 1.633 \\
\hline Default model & 46 & 0 & 0 & & \\
\hline Saturated model & 190 & 1056.595 & 171 & 0 & 6.179 \\
\hline Independence model & 19 & CMIN difference=13.491 & & \\
\hline DF difference=1 & & & & & \\
\hline
\end{tabular}

Since, in both cases, the difference between the CMIN differences $(50.714-13.491=37.227)$ is greater than 3.84 , the moderated effect of voluntariness on the relationship between subjective norm and perceived usefulness is statistically significant, supporting hypothesis $H 3 b$.

This study, therefore, found that whenever the employees feel that they are obliged to use the mobile phones at the workplaces, the influence of subjective norm to the perceived usefulness is impacted. The same applies when employee feel that they would impress their bosses on using or annoy their bosses for not using mobile phone technology to perform SME activities. To identify the type of this moderation relationship, the same procedure was employed and the results are seen in Table 8 in which standardized regression weights SN have on BI when a model is subjected under high voluntariness data and low voluntariness data are shown.

Table 8. Description of the impact of Voluntariness Moderation (SN-BI)

\begin{tabular}{|c|c|c|c|c|c|c|}
\hline \multicolumn{3}{|c|}{ Regression Weights: SN-BI High Voluntariness } & Estimate & S.E. & C.R. & $\mathrm{P}$ \\
\hline Behaviour_Intention & $\leftarrow$ & Subjective_Norm & 0.423 & 0.118 & 3.566 & $* * *$ \\
\hline \multicolumn{3}{|c|}{ Regression weights: SN-BI Low Voluntariness } & Estimate & S.E. & C.R. & $\mathrm{P}$ \\
\hline Behaviour_Intention & $\leftarrow$ & Subjective_Norm & 0.335 & 0.057 & 5.901 & $* * *$ \\
\hline
\end{tabular}

Table 8 reveals two main observations. Firstly, since the estimate at high voluntariness $(0.423)$ is greater than the estimate at low voluntariness $(0.335)$, the effect of subjective norm (SN) on behavior intention (BI) is more pronounced in high voluntariness to low voluntariness. This implies that when an employee of SMEs perceives that there is a mandated use of mobile phone technology in their workplaces the influence of subjective norm to the behaviour intention tends to be strengthened and the opposite is also true. 
Secondly, since the relationship between $\mathrm{SN}$ and $\mathrm{BI}$ on high voluntariness is statistically significant $(\mathrm{P}<0.05)$ in both situations of high and low voluntariness, then the moderation which exists is a partial moderation. That means, when voluntariness is very high, subjective norm tends to influence the behaviour intention whereas when the voluntariness is not there the influence of subjective norm to behaviour intention exists too but in small extent.

After testing the hypotheses for their significance, with an exception to the relationship between Perceived usefulness and behaviour intention, all the rest were found to be significant. This includes the moderation relationships of mandatoriness in which it was found to be significant in both relationships between Subjective norm and perceived usefulness and that of subjective norm and behaviour intention. The resulting evaluated model is shown in Fig 3.

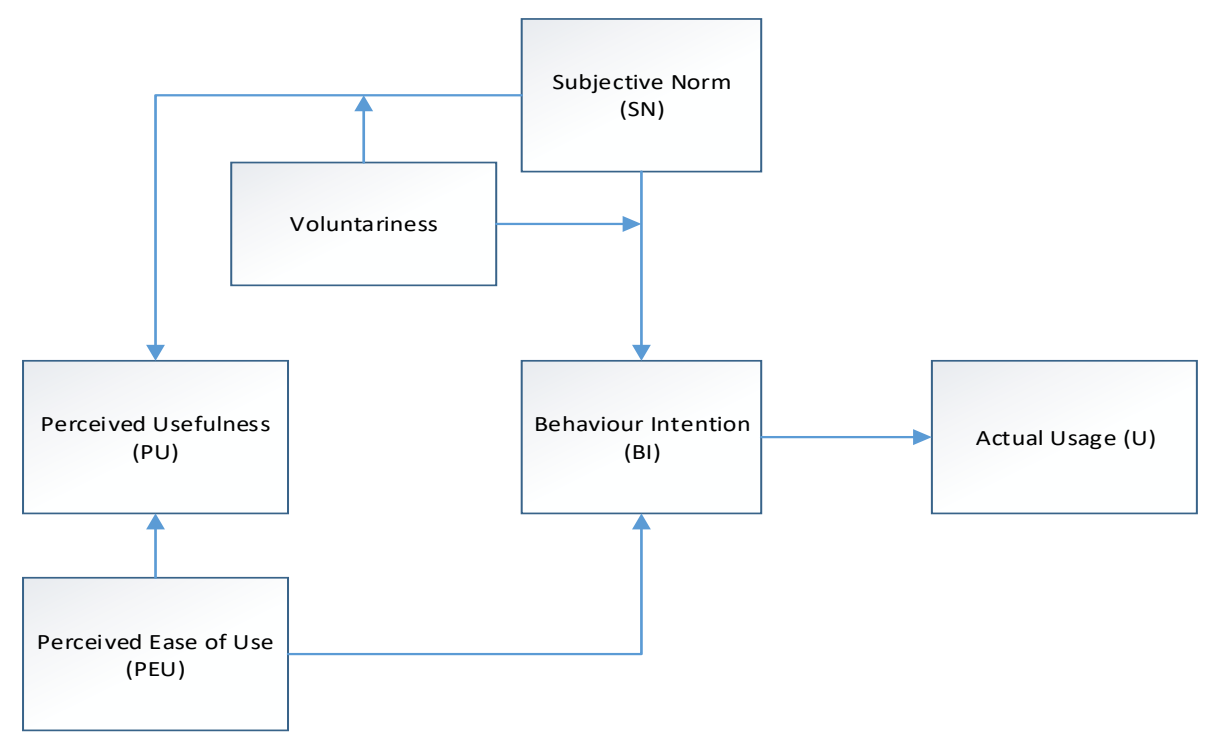

Fig.3. Final Evaluated Model

After performing the hypotheses testing, the resulting model is seen in Fig 3. In principle, that model explains mobile phone technology acceptance in mandatory situations, based on the context of SMEs.

\section{References}

[1] Awang, Z. (2015). SEM made simple: A gentle approach to learning Structural Equation Modeling. MPWS Rich Publication.

[2] Baraldi, A. N., \& Enders, C. K. (2010). An introduction to modern missing data analyses. Journal of School Psychology, 48(1), 5-37.

[3] Bhattacherjee, A., \& Sanford, C. (2004). Persuasion strategies for information technology usage: An elaboration likelihood model.

[4] Byomire, G., \& Maiga, G. (2015). A model for mobile phone adoption in maternal healthcare. In ISTAfrica Conference, 2015. IEEE.

[5] Chen, J. V., Yen, D. C., \& Chen, K. (2009). The acceptance and diffusion of the innovative smartphone use: A case study of a delivery service company in logistics. Information \& Management, 46(4), 241-248. 
[6] Davis, F. D. (1989). Perceived usefulness, perceived ease of use, and user acceptance of information technology. MIS Quarterly, 319-340.

[7] Fishbein, M., \& Ajzen, I. (1975). Belief, attitude, intention and behaviour: An introduction to theory and research. Retrieved from http://trid.trb.org/view.aspx?id=1150648

[8] Gallego, M. D., Luna, P., \& Bueno, S. (2008). User acceptance model of open source software. Computers in Human Behavior, 24(5), 2199-2216.

[9] Gribbins, M., Shaw, M., \& Gebauer, J. (2003). An investigation into employees' acceptance of integrating mobile commerce into organizational processes. AMCIS 2003 Proceedings, 11.

[10] Hair, J. F., Wolfinbarger, M. F., Ortinau, D. J., \& Bush, R. P. (2008). Essentials of marketing research. McGraw-Hill/Higher Education.

[11] Huber, E., \& Stephens, J. D. (1993). Political parties and public pensions: a quantitative analysis. Acta Sociologica, 36(4), 309-325.

[12] Kelman, H. C. (1958). Compliance, identification, and internalization: Three processes of attitude change. Journal of Conflict Resolution, 51-60.

[13] Kim, T. G., Lee, J. H., \& Law, R. (2008). An empirical examination of the acceptance behaviour of hotel front office systems: An extended technology acceptance model. Tourism Management, 29(3), 500-513.

[14] Kwon, H. S., \& Chidambaram, L. (2000). A test of the technology acceptance model: The case of cellular telephone adoption. In System Sciences, 2000. Proceedings of the 33rd Annual Hawaii International Conference on IEEE.

[15] Lindsay, R., Jackson, T. W., \& Cooke, L. (2011). Adapted technology acceptance model for mobile policing. Journal of Systems and Information Technology, 13(4), 389-407.

[16] Pedersen, P. E. (2005). Adoption of mobile Internet services: An exploratory study of mobile commerce early adopters. Journal of Organizational Computing and Electronic Commerce, 15(3), 203-222.

[17] Peng, R., Xiong, L., \& Yang, Z. (2012). Exploring Tourist Adoption of Tourism Mobile Payment: An Empirical Analysis. [17] Polit, D. F., \& Beck, C. T. (2006). The content validity index: are you sure you know what's being reported? Critique and recommendations. Research in Nursing \& Health, 29(5), 489497.

[18] Prieto, J. C. S., Migueláñez, S. O., \& García-Peñalvo, F. J. (2015). Mobile acceptance among pre-service teachers: a descriptive study using a TAM-based model. In Proceedings of the 3rd International Conference on Technological Ecosystems for Enhancing Multiculturality (pp. 131-137). ACM.

[19] Ruuska-Kalliokulju, S., Schneider-Hufschmidt, M., Väänänen-Vainio-Mattila, K., \& Von Noman, B. (2001). Shaping the Future of Mobile Devices. Results of the Workshop on Future Mobile Device User Interfaces at CHI 2000. SIGCHI Bulletin, 33, 16-21.

[20] Sun, Y., Wang, N., Guo, X., \& Peng, Z. (2013). Understanding the acceptance of mobile health services: a comparison and integration of alternative models. Journal of Electronic Commerce Research, 14(2), 183.

[21] Tassabehji, R., Wallace, J., \& Srivastava, A. (2008). Corporate Acceptance of M-Technology in the Service Sector: A Case Study. AMCIS 2008 Proceedings, 208.

[22] Van Biljon, J., \& Kotzé, P. (2007a). Modelling the Factors That Influence Mobile Phone Adoption. In Proceedings of the 2007 Annual Research Conference of the South African Institute of Computer Scientists and Information Technologists on IT Research in Developing Countries (pp. 152-161). New York, NY, USA: ACM. https://doi.org/10.1145/1292491.1292509

[23] Venkatesh, V. (2000). Determinants of perceived ease of use: Integrating control, intrinsic motivation, and emotion into the technology acceptance model. Information Systems Research, 11(4), 342-365.

[24] Venkatesh, V., \& Bala, H. (2008). The technology acceptance model 3 and a research agenda on interventions. Decision Sciences, 39(2), 273-315.

[25] Venkatesh, V., \& Davis, F. D. (2000). A theoretical extension of the technology acceptance model: Four longitudinal field studies. Management Science, 46(2), 186-204.

[26] Venkatesh, V., Morris, M. G., Davis, G. B., \& Davis, F. D. (2003). User acceptance of information technology: Toward a unified view. MIS Quarterly, 425-478. 
[27] Yueh, H.-P., Lu, M.-H., \& Lin, W. (2015). Employees' acceptance of mobile technology in a workplace: An empirical study using SEM and fsQCA. Journal of Business Research. Retrieved from http://www.sciencedirect.com/science/article/pii/S0148296315006736

[28] Zhao, Y., \& Cavusgil, S. T. (2006). The effect of supplier's market orientation on manufacturer's trust. Industrial Marketing Management, 35(4), 405-414.

\section{Author's Profile}

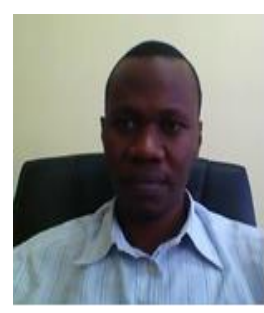

Renatus Mushi is a lecturer in the department of Computer Science holding a Master's degree in Computing (Information Technology) from Dublin Institute of Technology (DIT), Ireland in 2009 and Bachelor degree in Computer Engineering \& Information Technology from University of Dar es Salaam in 2007. He is currently a PhD student at DIT, Ireland. Renatus is interested in information systems management, systems analysis and design, software projects management and decision sciences. He has been involved in various consultancy activities such as evaluating and implementing strategic ICT plans and ICT policies. Internationally, Renatus has been an active member in setting up, executing and monitoring the Global Entrepreneurial Talent Management (GETM 3) project where he has been travelling and working with international experienced researchers from the leading universities such as Kyungpook National University (Daegu, South Korea), Northumbria University (Newcastle, UK) and Warsaw University of Technology (Warsaw, Poland).

How to cite this paper: Renatus Mushi, "The Moderating Effect of Mandatoriness on the Acceptance of Mobile Phone Technology: SMEs Perspective ", International Journal of Wireless and Microwave Technologies(IJWMT), Vol.8, No.5, pp. 46-59, 2018.DOI: 10.5815/ijwmt.2018.05.06 